\title{
Pesquisa
}

\section{A IMPORTÂNCIA DA AFETIVIDADE NA RELAÇÃO PROFESSOR ALUNO}

\author{
Maria Suzana Sobral Braga Gondim (1) \\ Eliane Maria dos Santos Costa (2)
}

\begin{abstract}
Resumo
O presente estudo buscou, através de pesquisa bibliográfica, um conhecimento sobre a importância da afetividade no processo ensino/aprendizagem. Com as transformações rápidas que tem acometido o mundo, a escola tem incentivado cada vez mais o desenvolvimento cognitivo e a capacidade do aluno para sobressair-se profissionalmente. A força da educação calcada no afeto, tende a moldar o espírito de compreensão e solidariedade entre as pessoas, por isto deve ser trabalhado para levar o aluno a perceber o lado positivo da sua existência. No processo de desenvolvimento do emocional, o professor aparece como mediador do afeto, em conjunto com a escola e a família, uma vez que a afetividade acompanha o indivíduo desde o nascimento estendendo-se por toda sua vida. A educação baseada no respeito, na atenção e no afeto, leva o educando a ser mais compreensivo, mais seguro de si mesmo e a firmar sua personalidade com mais autonomia e maior capacidade de tomar decisões mais acertadas nas situações diversas da sua vida.
\end{abstract}

Palavras-chave: Afetividade, Educação, Aprendizagem

\section{Introdução}

São cada vez mais freqüentes as notícias sobre crianças abandonadas, nas ruas, sem freqüentar escolas, consumindo drogas, sofrendo abusos sexuais e feridas na sua dignidade. 
Que atrativos essas crianças teriam para ficar em suas casas, para assistirem às aulas? Suas necessidade de afeto, de carícias, de amor e respeito seriam atendidas?

As transformações na sociedade ocorrem tão rapidamente, exigindo constante aperfeiçoamento da vida profissional, enquadrando as pessoas a um modelo determinado pela cultura: "vencer a qualquer custo". Muitas vezes prevalece o individualismo, a necessidade do TER, a falta de tempo para os filhos- tempo para parar e analisar que além de tudo isso, é fundamental o afeto, o respeito, o diálogo, a amizade. "A busca pela felicidade pode apoiar-se na simplicidade e na imensa alegria do SER, suplantando a ambição consumista do TER" (ANTUNES, 1999).

As pessoas já nascem com necessidades: de amor, de proteção, de afeto, de educação, da orientação de outras pessoas para suprir essas necessidades. De acordo com Aranha (1992, p.26) "O homem é um ser de desejo. E como surge o desejo? Surge à medida que o homem estabelece relações com a natureza, com os outros homens, ocasião em que vivencia emoções e sentimentos, isto é, reage afetivamente aos acontecimentos."

Em muitas escolas o conhecimento intelectual é mais importante. A educação limitase a repassar informações, mostrar caminhos que o professor considera mais correto, preparar para vestibular ou para concurso. A educação está baseada mais no controle que no afeto, no autoritarismo do que na colaboração. Porém, tão importante é o equilíbrio emocional, o desenvolvimento de atitudes positivas diante de si mesmo e dos outros, o viver em grupo, as interações sociais.

O professor deve estar preparado para avaliar as alternativas e escolher a melhor opção para lidar com as situações do ensino/aprendizagem. O prazer em aprender é fundamental. A afetividade é a energia que desperta no aluno o gosto pelo aprender.

Muito se fala em inteligência emocional, em desenvolver a confiança e a autoestima, porém pouco se faz em algumas escolas, para uma melhor contribuição numa formação mais equilibrada da personalidade do aluno. Menos ainda com relação a uma real integração no ambiente sócio-cultural em que vive, através do ajustamento de seus sentimentos, atitudes e ideais.

De acordo com Campos, (1992), é diante de um novo conhecimento ou habilidade, que a atitude do aprendiz pode variar. Dessa forma pode se revelar positiva, negativa ou mesmo indiferente. A aprendizagem apreciativa, emocional ou afetiva sempre acompanha as demais, transcendendo o currículo escolar.

O que se aprende é o que se vive. Então porque não unir a transmissão de conhecimentos de forma atrativa, com modelos que desenvolvam formas participativas, 
humanas, com afetividade, com solidariedade? Este modelo certamente formará seres aptos a encarar a vida com autoconfiança, com coleguismo. O professor deve ter o cuidado de manter um bom ajustamento afetivo com seus alunos, para dessa forma, desenvolver no educando a confiança de saber que pode ter apoio no seu aprendizado.

Segundo Rosenfeld (2007, pág. 59) “talvez o significado mais marcante de nosso trabalho e de maior alcance futuro seja simplesmente nosso modo de ser e agir enquanto equipe." Sempre se fala em idéia de conjunto, de reciprocidade. Na educação, conforme a mesma autora, "podemos ajudar a desenvolver o potencial que cada aluno tem, dentro de suas possibilidades e limitações. Para isso precisamos praticar a pedagogia da compreensão contra a pedagogia da intolerância...”.

O presente trabalho tem como objetivo verificar se a pedagogia baseada na compreensão, ou pedagogia do afeto, como instrumento de ensino/aprendizagem interfere na relação professor/aluno. Também pretende compreender de que forma a afetividade pode contribuir na aprendizagem do educando. A pesquisa será realizada através de estudos bibliográficos.

Segundo Chalita (2003), o afeto deveria reger todos os relacionamentos, todas as ações, todos os vínculos, pois seria uma centelha divina, uma partícula de amor no espaço universal.

\section{Ensino e Aprendizagem}

Para se falar em afetividade na relação professor/aluno e sua importância no ensino/aprendizagem, devem-se descrever um pouco sobre ensino/aprendizagem.

A aprendizagem acompanha o indivíduo desde o início de sua existência. De acordo com Campos (1987, p.16) ela capacita o homem a ajustar-se ao seu ambiente físico e social: "explicar o mecanismo da aprendizagem é esclarecer a maneira pela qual o ser humano se desenvolve, toma conhecimento do mundo em que vive, organiza sua conduta e se ajusta ao meio físico e social". Libâneo (1994) concorda que através da aprendizagem, o homem se afirma como ser racional, forma sua personalidade e se prepara para o papel que lhe cabe no seio da sociedade. E continua definindo o processo de ensino, como atividade de mediação onde são dadas condições e meios para que o aluno assimile determinados conhecimentos, orientados e de forma organizada. Assim traduz o autor, 
"O ensino tem a tarefa principal de assegurar a difusão e o domínio dos conhecimentos sistematizados legados pela humanidade. Daí que uma de suas tarefas básicas sejam a seleção e organização do conteúdo de ensino e dos métodos apropriados, a serem trabalhados num processo organizado de sala de aula”. LIBÂNEO, (1994, p 54)

Neste caso, o autor sugere que ensinar e aprender são duas facetas do mesmo processo, e que se realizam em torno das matérias de ensino, sob a direção do professor. $\mathrm{O}$ processo de ensino, além de transmissão de informações, é também o meio de organização das atividades de estudo dos alunos. Neste caso, “o ensino somente é bem sucedido quando os objetivos do professor coincidem com os objetivos de estudo do aluno e é praticado tendo em vista o desenvolvimento de suas forças intelectuais" (LIBÂNEO, 1994, p.83). O professor planeja, dirige e controla o processo de ensino, tendo em vista estimular e suscitar a atividade própria dos alunos para a aprendizagem.

A relação ensino/aprendizagem é recíproca, destacando-se o papel dirigente do professor e a atividade dos alunos. O objetivo do ensino é estimular, incentivar, impulsionar o processo de aprendizagem dos alunos. Para isso, faz parte das atividades do professor organizar, selecionar e explicar os conteúdos e organizar atividades de estudo com meios adequados para uma melhor aprendizagem dos alunos.

De acordo com Libâneo (1994), aprendizagem é a atividade do aluno de assimilação de conhecimentos e habilidades e, o processo de ensino deve estabelecer exigências e expectativas que os alunos possam cumprir, pois tem prioritariamente o papel de impulsionar a aprendizagem deste.

A principal preocupação das escolas é o conhecimento intelectual e atualmente a importância do equilíbrio emocional, o desenvolvimento de atitudes positivas diante de si mesmo e dos outros, Aprender a viver em sociedade, em grupo, é também uma experiência necessária para desenvolver nos alunos a autoconfiança e o potencial de cada um em áreas específicas.

\section{Relação professor/aluno}

A sociedade cobra muito das escolas, especificamente dos professores, papéis que cabem à família, como necessidades de afeto, resolução de problemas de violência, drogas, 
indisciplinas; esperam que eles preparem melhor os seus alunos, em áreas diversas, para que no futuro esses alunos tenham melhores condições de enfrentarem competitividade.

O professor não vai substituir a família. De acordo com Oliveira (2005, pág.32).

“A formação do professor deve trabalhar certos sentimentos que a atuação profissional lhes desperta e estimulá-los a examinar os conflitos surgidos na relação interpessoal com a criança e com sua família [...] a formação dos professores deve buscar desenvolver-lhes a capacidade de estabelecer com as crianças relações cordiais, acolhedoras, sintonizadas, estimuladoras, balizadoras de limites".

É importante que a escola ofereça, além de condições físicas satisfatórias, um ambiente onde haja um clima de coletividade. Dessa forma, os alunos são incentivados a colaborar com o bem-estar comum e fortalecer traços de solidariedade, amor pela escola e dedicação aos estudos, para um melhor aproveitamento escolar.

Para Oliveira, nas escolas, o professor é o parceiro no processo de desenvolvimento da criança, "sua função é a de ser uma pessoa verdadeira que se relacione afetivamente com a criança, garantindo-lhe a expressão de si, visto que ela precisa de alguém que acolha suas emoções e, assim, lhe permita estruturar seu pensamento" (2005, pág. 203).

As interações entre as crianças e seus professores além de contribuir para a construção de informações, habilidades e conhecimentos sobre objetos do mundo, desenvolvem também a construção de uma ética, uma noção política e uma identidade pessoal.

Na observação de seus alunos no cotidiano da escola, verificando suas reações, incentivando-os a partilhar as atividades, despertando o desejo de trabalhar em grupo, o professor pode descobrir melhores caminhos para a formação de vínculos afetivos produtivos para o desenvolvimento dos alunos. "A forma como o professor desempenha seu papel de autoridade é particularmente importante, visto que a criança com freqüência o imita na interação com os companheiros". (OLIVEIRA, 2005, PÁG. 211)

Libâneo valoriza a relação professor-aluno como incentivo ao estudo. Há uma satisfação pessoal do aluno na ampliação de seus conhecimentos, e "a estimulação para o estudo depende do elogio e da valorização do professor diante do bom desempenho dos alunos. Isto contribui para que o aluno cultive uma imagem positiva de si mesmo" (1994, p.113). 
O professor equilibrado, aberto, encanta. A educação hoje, ainda está baseada mais no controle que no afeto. $\mathrm{O}$ professor de bem com suas emoções transmite em suas palavras e gestos, clareza, reforço e, se esta transmissão for feita com tranqüilidade, o aluno capta a mensagem.

A afetividade é componente básico do conhecimento e está ligado ao sensorial e ao intuitivo; a afetividade se manifesta mais efetivamente em clima de acolhimento e empatia.

\section{Aprendizagem apreciativa ou afetiva}

A afetividade, segundo Campos, influi, modifica e aperfeiçoa a personalidade do educando. E esta está estruturada sob as bases hereditárias em constante interação com o meio ambiente: "a aprendizagem apreciativa compreende atitudes, valores sociais, traduzidos por gostos, preferências, simpatias, costumes, crenças, hábitos e ideais de ação que constituem os princípios mais gerais de conduta humana" (1987,P.69).

A afetividade interfere na escolha ou rejeição de determinados objetivos e na valorização de algumas situações por parte da criança. Na prática pedagógica, sentimentos de atração ou de repulsão podem surgir na relação professor/aluno, dependendo de como este aluno é tratado no seu dia a dia.

Almeida (1999) comenta:

"A afetividade, assim como a inteligência, não aparece pronta nem permanece imutável, ambas evoluem ao longo do desenvolvimento; são construídas e se modificam de um período a outro, pois, à medida que o individuo se desenvolve, as necessidades afetivas se tornam cognitivas...”.

Oliveira (2005, p.65) observa: 'Pestallozzi considerava que a força vital da educação estaria na bondade e no amor, tal como na família, e sustenta que a educação deveria cuidar do desenvolvimento afetivo das crianças desde o nascimento".

Este cuidar, é olhar o outro com empatia, com afeto, com respeito, com compreensão, com nossas atitudes que as crianças observam.

Tiba (2002, P.82), afirma que, "a criança aprende pelo relacionamento afetivo que outro ser humano estabelece com ela e também com o que presencia do relacionamento entre 
seus pais. Por isso todo cuidado é pouco". O mesmo autor diz que a educação pode ser realizada a seis mãos: mãe, pai e escola, através das duas mãos, a do coração (afeto e sentimento) e a da cabeça (razão e pensamento).

A aprendizagem afetiva também influi no caráter do aprendiz o que se expressa na sua maneira de agir diante de situações diferentes do dia a dia, na sua capacidade para avaliar o que é verdadeiro, de apreciar o belo e praticar o bem.

Segundo Campos o processo de aprendizagem é contínuo, estando presente no início da vida, na escola e na vida adulta. Como processo contínuo a pessoa também pode aprender algo que prejudique o bom desenvolvimento de sua personalidade. "Por isso a família, a escola e enfim todos os agentes educacionais precisam selecionar os conteúdos e comportamentos a serem exercitados" (1987, p.35). O respeito, a valorização dos indivíduos, o afeto, a compreensão entre as pessoas são também valores a serem transmitidos, além dos aspectos cognitivos.

Para Morin (1999), a compreensão não pode ser quantificada. No educar para a compreensão humana encontra-se a missão espiritual da educação: ensinar a compreensão entre as pessoas como condição e garantia da solidariedade intelectual e moral da humanidade. Se soubermos compreender antes de condenar, estaremos no caminho da humanização das relações humanas.

Conforme Antunes, "educam-se emoções para que o aluno conheça-se melhor, compreenda que sentimentos de solidariedade e empatia não surgem tão espontaneamente quanto se imaginava antes..." Os alunos devem ser estimulados, treinados constantemente para que sejam criados vínculos de afetividade, de amor, para que ele goste do seu professor e tenha interesse em aprender.

O prazer em aprender tem grande influência na aprendizagem e é de extrema importância na relação que se estabelece entre o aluno e o conhecimento.

Rubem Alves (2005) concorda que quando se aprende algo, se gosta por se gostar da pessoa que a ensina. Quando temos admiração por um mestre, o coração dá ordens à inteligência para aprender as coisas que a mente sabe.

Dessa forma, aprendemos porque admiramos, pois todos somos movidos pelo desejo. As crianças aprendem movidas pelo desejo. 


\section{Considerações Finais}

Pelo estudo realizado através de pesquisa bibliográfica verificou-se que vários autores abordam a questão da afetividade, da compreensão entre as pessoas, do diálogo e do respeito entre alunos e seus professores, como parte importante da sua formação. Observou-se também que a maioria das escolas prioriza as capacidades cognitivas do aluno, o acúmulo de informações para colocar este aprendiz no mercado de trabalho.

Segundo os diversos autores estudados, o aluno necessita de uma aprendizagem que o faça assimilar conhecimentos e habilidades e além disto é importante que a escola ofereça, além de condições físicas satisfatórias onde tenha capacidade de desenvolver-se física e intelectualmente, um ambiente satisfatório, um clima de coletividade, que os alunos sejam incentivados a colaborar com o bem estar do ambiente em que convive e desenvolver a solidariedade entre as pessoas, o amor pela escola, dedicação aos estudos e respeito ao próximo.

É importante também no desenvolvimento das crianças, trabalhar a questão dos limites. Nesta empreitada, o professor deve ser o parceiro, estimulando a aprendizagem, observando as emoções, as reações, incentivando a partilhar as atividades de sala de aula, o trabalhar em grupo, sendo uma pessoa verdadeira. Deve ainda procurar desempenhar seu papel com autoridade, respeito, afeto, ajudando-os a estruturar seus pensamentos com segurança, uma vez que o aluno frequentemente imita seu mestre.

A afetividade influi, modifica e aperfeiçoa a personalidade do educando ao longo de sua vivência em interação com o ambiente. Tem bases hereditárias mas vai aperfeiçoando de acordo com preferências, costumes, crenças, hábitos e ideais de ação. Se afetividade interfere na escolha ou rejeição de determinados objetivos e na atração ou repulsão na reação entre pessoas, então uma educação baseada na bondade e no amor, na compreensão entre as pessoas, pode ser o caminho da humanização das relações humanas, segundo Morin (1999).

Rubem Alves (2005), entre tantos autores, afirma que o prazer em aprender influencia a aprendizagem e tem grande importância na relação entre professor/aluno. Ele compara o professor ao cozinheiro que tem o prazer de cozinhar bem, que gosta do que faz. Ao preparar os alimentos, ele escolhe com calma, concentração os ingredientes que irão dar melhor sabor e aparência mais atrativa ao prato final. Assim deve ser o professor, escolher com tranqüilidade, dentre tantos planejamentos que dispõe, aquele que melhor encante seus alunos, que os desperte a saborear os conhecimentos que se queira transmitir, que conquiste a atenção, que resulte numa aprendizagem com indivíduos participativos, que se sintam parte de 
um processo que desenvolva cidadãos ativos, conscientes, aptos a viver bem sua história de vida.

O ser humano necessita de afeto, carinho, atenção, respeito. Em tudo na vida, o indivíduo responde melhor ao toque, a um carinho, para saber que é bem vinda a sua presença. $\mathrm{O}$ aluno tem mais prazer em conviver com um professor que o escute, que o veja e que perceba seus sentimentos. Rubem Alves sempre enfatiza que frequentemente se aprende uma coisa de que não se gosta, por se gostar da pessoa que a ensina. É o modo como você prepara o alimento que faz a criança comer com gosto, é a maneira com você age em sala de aula. O professor de bem com suas emoções, com empatia, confiança, amor, tranqüilidade, tende a refletir em uma maior facilidade do aluno em captar essa mensagem.

O professor pode não ser o culpado pelo sucesso ou insucesso da aprendizagem de seus alunos. São muitos os motivos que ele pode ter para estar desmotivado com a educação. Mas o que se deve perceber é a carência de afetividade que se observa no mundo atual, quando se vê jovens praticando crimes por ciúmes, por acharem que são donos uns outros, por falta de limites, por falta de amor ou de afeto. Ao professor não cabe o papel de pais de seus alunos, mas deve procurar fazer o melhor de si para ajudar, em conjunto com a escola e com os pais dessas crianças a formar um ambiente mais solidário, mais tranqüilo, onde essas crianças sintam que haja uma clima de mais afetividade, que saibam que são importantes no processo de descobrir um mundo melhor, de respeito, de solidariedade.

\section{Referências}

ALMEIDA, A. R. S. A emoção na sala de aula. Campinas: Papirus, 1999.

ALVES, Rubem. O prazer da leitura. Disponível em: http://www.rubemalves.com.br/ oprazerdaleitura.htm. Acesso em: 10/03/05.

ANTUNES, Celso. Alfabetização emocional: novas estratégias. Petrópolis, RJ: Vozes, 1999. ARANHA, Maria Lúcia de Arruda; MARTINS, Maria Helena Pires. Temas de filosofia. São Paulo: Editora Moderna, 1992.

BOFF, Leonardo. Saber cuidar: ética do humano - compaixão pela terra. Petrópolis, RJ: Vozes, 1999. 
CAMPOS, Dinah Martins de Souza. Psicologia da Aprendizagem. Petrópolis: Editoras Vozes, 1987.

CHALITA, Gabriel. Pedagogia do amor: a contribuição das histórias universais para a formação de valores das novas gerações. São Paulo: Editora Gente, 2003.

LIBÂNEO, José Carlos. Didática. São Paulo: Cortez, 1994.

MINAYO, Maria Cecília Souza. Pesquisa social: teoria, método e criatividade. Petrópolis: Editora Vozes, 2002.

MORIN, Edgar. Por quê e Como Articular os Saberes: Relatório de Edgar Morin. In: http://www.cndp.fr/colloquilyae/ morin_final.htm Setembro de 1999.

OLIVEIRA, S. L. Tratado de metodologia científica: projetos de pesquisas, TGI, TCC, monografias, dissertações e teses. São Paulo: Pioneira, 1997.

OLIVEIRA, Zilma Ramos. Educação infantil: Fundamentos e métodos. São Paulo: Editora Cortez. 2005.

ROSENFELD, Marina. A educação que desejamos: Novos desafios e como chegar lá. Editora Papirus, 2007. Disponível em: http://www.educaçãoonline.pro.br/ . Acesso em: fev.2008.

SHINYASHIKI, Roberto. A carícia essencial: uma psicologia do afeto. São Paulo: Gente, 2005.

TIBA, Içami. Ensinar aprendendo: como superar os desafios do relacionamento professoraluno em tempos de globalização. São Paulo: Gente, 1998.

Quem ama. Educa. São Paulo: Gente, 2002.

TOBAR, F.; YALOUR, M. R. Como fazer teses em saúde pública. Rio de Janeiro: Fiocruz, 2001.

Sobre as autoras:

(1) Maria Suzana Sobral Braga Gondim é graduada em Biologia e Pós-graduada em Psicologia Aplicada à Educação pela Universidade Regional do Cariri - URCA. E-mail: suzi.sobral @ yahoo.com.br

(2) Eliane Maria dos Santos Costa é graduada em Pedagogia e Pós-graduada em Psicologia Aplicada à Educação pela Universidade Regional do Cariri- URCA. 